\title{
Patterns of Thyroid Function in Metabolic Syndrome Patients and Its Relationship with Components of Metabolic Syndrome
}

\author{
Nazma Akter ${ }^{1, ~ *, ~ Z a f a r ~ A h m e d ~ L a t i f ~}{ }^{2}$ \\ ${ }^{1}$ Department of Medicine, MARKS Medical College \& Hospital, Dhaka, Bangladesh \\ ${ }^{2}$ BIRDEM General Hospital, Dhaka, Bangladesh
}

Email address:

nazma_aktar_endo@yahoo.com (N. Akter)

${ }^{*}$ Corresponding author

\section{To cite this article:}

Nazma Akter, Zafar Ahmed Latif. Patterns of Thyroid Function in Metabolic Syndrome Patients and Its Relationship with Components of Metabolic Syndrome. International Journal of Diabetes and Endocrinology. Vol. 6, No. 2, 2021, pp. 80-87. doi: 10.11648/j.ijde.20210602.15

Received: May 10, 2021; Accepted: June 4, 2021; Published: June 16, 2021

\begin{abstract}
Background: Metabolic syndrome (MetS) is a cluster of metabolic abnormalities characterized by central obesity, hyperglycemia plus insulin resistance, hypertriglyceridaemia plus low high density lipoprotein (HDL) cholesterol and hypertension. This cluster of metabolic syndrome is associated with some of the endocrine disorders prominently thyroid dysfunction. Thyroid dysfunction and metabolic syndrome are both associated with cardiovascular disease risk conversely increasing both morbidity and mortality. Objectives: This study was carried out to evaluate thyroid function in patients with metabolic syndrome and to assess its relationship with the components of metabolic syndrome in a tertiary care hospital. Methods: A cross sectional study was carried out among metabolic syndrome patients attending Hormone and Diabetes clinic in a tertiary care hospital, Dhaka, Bangladesh during June 2019 to March 2020. We included 346 patients who fulfilled National Cholesterol Education Program-Adult Treatment Panel (NCEP ATP) III criteria. Anthropometric parameters include; height, weight and waist circumference were measured and blood pressure were taken in standard conditions. Fasting blood samples were analyzed to measure glucose, triglyceride (TG), high density lipoprotein (HDL) cholesterol and thyroid hormones [Thyroid stimulating hormone (TSH) and Free Thyroxine (FT4)]. Patients categorized as euthyroid if all thyroid hormone levels fell within normal reference range [TSH: 0.47-5.0mIU/L; FT4: 0.71-1.85 ng/dL]. Subclinical hypothyroidism $(\mathrm{SCH})$ was considered if TSH $>5.0 \mathrm{mIU} / \mathrm{L}$ and free T4 is within normal reference value $(0.71-1.85 \mathrm{ng} / \mathrm{dL})$. Conversely, overt hypothyroidism was diagnosed if TSH $>5.0 \mathrm{mIU} / \mathrm{L}$ and freeT4<0.71 ng/dL. Results: Among study population $22.8 \%$ were males and $77.2 \%$ were females, with mean age of $42.61 \pm 9.13$ years. Average body mass index (BMI) of the study subjects was $26.37 \pm 3.78 \mathrm{~kg} / \mathrm{m}^{2}$. Thyroid dysfunction was seen in $47.1 \%$ of metabolic syndrome patients. The prime thyroid dysfunction was subclinical hypothyroidism (34.4\%) followed by overt hypothyroidism (12.7\%). Thyroid dysfunction was much common in females $(37.3 \%)$ than males $(9.9 \%)$ but was not statistically significant; $[\mathrm{p}=0.19]$. Triglyceride showed significant positive correlation with TSH level $(\mathrm{r}=0.168, \mathrm{p}<0.05)$ but negative correlation with free $\mathrm{T} 4(\mathrm{r}=-0.200, \mathrm{p}=<0.001)$. However, HDL cholesterol showed significant negative correlation with TSH level $(\mathrm{r}=-0.150, \mathrm{p}<0.05)$. Conclusions: Our study recognizes thyroid dysfunction in metabolic syndrome patients; subclinical hypothyroidism was the commonest followed by overt hypothyroidism. The current study also correlates thyroid function with some components of metabolic syndrome (high density lipoprotein cholesterol and triglycerides).
\end{abstract}

Keywords: Metabolic Syndrome, Thyroid Dysfunction, Subclinical Hypothyroidism, Hypothyroidism

\section{Introduction}

The prevalence of metabolic syndrome is increasing all over the world with apparent evidence of high prevalence in
India and some other South Asian countries [1]. Metabolic syndrome (MetS) is a cluster of metabolic abnormalities characterized by central obesity, hyperglycemia plus insulin resistance, hypertriglyceridaemia plus low high density 
lipoprotein (HDL) cholesterol and hypertension [1]. Some of the cardiovascular risk factors like hypertension, atherogenic dyslipedemia, prothrombotic and proinflammatory conditions constellated with metabolic syndrome [2]. Among different thyroid dysfunction status group, subclinical hypothyroidism has been observed more frequently in metabolic syndrome patients than general population [1].

Both Thyroxine and Triidothryronine play prime part in maintaining thermogenesis and metabolic homeostasis [3]. Thyroid functions affect the different components of MetS including HDL-cholesterol (HDL-C), triglycerides (TG), blood pressure and plasma glucose. However, the impact of various degree of thyroid dysfunction (TD) on different components of MetS is still debatable [4]. Consequently both MetS and hypothyroidism are perceived risk factors for atherosclerotic cardiovascular disease (CVD) and augmented risk for cardiovascular morbidity and mortality [5]. Some study also reported about higher thyroid stimulating hormone (TSH) level in metabolic syndrome patients than in healthy group, and high prevalence of metabolic syndrome in subjects with higher TSH level than normal as compared to those with normal TSH level [6]. As metabolic syndrome and hypothyroidism are independent risk factors for cardiovascular disease, it is feasible that patients suffering from both these disease entities may have a compounded risk [5]. There is also evidence to asses thyroid function in patients with metabolic syndrome who are at higher risk for CVD [7].

Thyroid dysfunction is common in Bangladesh. The prevalence of metabolic syndrome is also high and uprising here in Bangladesh. According to a report from a systematic review and meta-analysis the prevalence of MetS is $37 \%$ based on Modified National Cholesterol Education Program Adult Treatment Panel III (NCEP ATP III) criteria [8]. Though, thyroid function in such patients is not well examined in Bangladeshi population. The present study was conducted among metabolic syndrome patients attending a tertiary care hospital in Dhaka, Bangladesh to evaluate thyroid function in patients with metabolic syndrome and to assess its relationship with the components of metabolic syndrome

\section{Methods}

\subsection{Study Design}

A cross sectional study was carried out among randomly selected metabolic syndrome patients attending a Hormone \& Diabetes clinic in a tertiary care hospital, Dhaka, Bangladesh during June 2019 to March 2020.

\subsection{Operational Definitions}

\subsubsection{Metabolic Syndrome}

Metabolic syndrome was defined according to the criteria of the modified NCEP ATP III. According to the modified NCEP ATP III criteria [9], the presence of any three of the following five factors is required for a diagnosis of Metabolic
Syndrome (MetS): abdominal obesity, hypertriglyceridaemia (TG $>150 \mathrm{mg} / \mathrm{dL}$ ); low HDL cholesterol (HDL-C $<40 \mathrm{mg} / \mathrm{dL}$ in males and $<50 \mathrm{mg} / \mathrm{dL}$ in females); elevated blood pressure (systolic blood pressure $\geq 130 \mathrm{mmHg}$ and/or diastolic blood pressure $\geq 85 \mathrm{mmHg}$ or current use of antihypertensive drugs); impaired fasting blood glucose (FBG) $(\geq 5.6 \mathrm{mmol} / \mathrm{L})$ or on anti- diabetic medications. The modified NCEP ATP III criteria suggested the cut-off points of waist circumference should be ethnic specific where individuals of Asian origin should use the cut-off of $90 \mathrm{~cm}$ in men and $80 \mathrm{~cm}$ in women [10].

\subsubsection{Thyroid Dysfunction}

Patients were said to be euthyroid if all thyroid hormone levels fell within reference range [TSH (Thyroid stimulating hormone): $0.47-5.0 \mu \mathrm{IU} / \mathrm{mL}$; FT4 (Free thyroxine): 0.71-1.85 $\mathrm{ng} / \mathrm{dL}$. Metabolic syndrome patients were considered to have thyroid dysfunction if patients' thyroid hormones level fell outside the reference range. Subclinical hypothyroidism ( $\mathrm{SCH}$ ) was considered if $\mathrm{TSH}>5.0 \mu \mathrm{IU} / \mathrm{mL}$ and free $\mathrm{T} 4$ is within normal reference value (0.71-1.85 ng/dL). Overt or clinical hypothyroidism was defined as $\mathrm{TSH}>5.0 \mu \mathrm{IU} / \mathrm{mL}$ and freeT $4<0.71 \mathrm{ng} / \mathrm{dL}$.

\subsection{Study Subjects}

In the present study, 346 patients who fulfilled the modified National Cholesterol Education Program-Adult treatment Panel (NCEP-ATP) III (3out of 5 criteria positive) criteria [11] was recruited. We used self-reported diagnosis of diabetes mellitus and hypertension for this study. Patients known as smokers, alcoholics or having acute or chronic illnesses such as coronary heart disease, renal failure, pancreatitis, liver or renal disorders, and pregnant women were excluded from study. Patients were also being excluded who had previous thyroid disorders or under treatment of any thyroid related disorders.

\subsection{Data Collection}

After getting approval of appropriate authority and taking consent from the individuals fulfilling the inclusion criteria of the study, a predesigned structured questionnaire was administered and filled by the doctor attending the patient. The detailed history of all such patients was taken, and physical and relevant clinical examinations were performed.

\subsubsection{Anthropometric and Clinical Assessments}

Anthropometric measurements of height and weight were measured. The waist circumference (WC) was measured in a horizontal plane, mid way between the inferior margin of the $12^{\text {th }}$ ribs and the superior border of the iliac crest. The blood pressure was measured by a manual sphygmomanometer in sitting conditions (measured 2 times after a 5-min rest between each measurement [12].

\subsubsection{Laboratory Investigations}

The blood was collected from the median cubital vein 10- 
12 hours after the last meal (fasting blood) for the estimation of serum FT4, TSH, lipid profile and FBS. The blood samples then centrifuged to separate the serum and divided into 3 parts for thyroid profile, lipid profile and fasting blood sugar. All investigations were done with well standard laboratory procedure.

For thyroid profile, first part of the serum was analyzed by Advia Centaur CP Imunoassay analyzer. The second part of the serum was analyzed on chemistry analyzer; Dimensions Rx Max by using the Siemens kit for TG and HDL-C. And third part of serum samples was used for fasting glucose analysis on a glucose analyzer (Beckman Coulter, Auto Analyzer).

\subsection{Statistical Analysis}

Data were analyzed with SPSS Inc, Chicago, Illinois, USA software version 18 . The means and standard deviations were used to describe continuous data. For categorical data, frequencies and percentages were estimated. Categorical variables were compared with each other using the chi-square test. Pearson correlation test was used to find relationship between thyroid function and components of metabolic syndrome. Correlation was expressed as Pearson correlation coefficient (r). P value $<0.05$ was considered as significant.

\section{Results}

\subsection{Baseline Characteristics}

The study population comprised of $22.8 \%(n=79)$ males and $77.2 \% \quad(n=267)$ females, with mean $( \pm S D)$ age of $42.61 \pm 9.13$ years. Mean ( \pm SD) height, weight, body mass index (BMI) of study subjects were $1.55 \pm 6.71 \mathrm{~m}, 63.91 \pm 9.36$ $\mathrm{kg}, \quad 26.37 \pm 3.78 \mathrm{~kg} / \mathrm{m}^{2}$ respectively. Laboratory findings revealed the mean fasting blood glucose; triglyceride, HDL cholesterol; free T4 and TSH were $7.51 \pm 2.98 \mathrm{mmol} / \mathrm{L}$, $180.94 \pm 67.04 \mathrm{mg} / \mathrm{dL}, 33.07 \pm 8.01 \mathrm{mg} / \mathrm{dL}, 1.06 \pm 0.22 \mathrm{ng} / \mathrm{dL}$, $5.63 \pm 3.34 \mu \mathrm{IU} / \mathrm{mL}$ respectively; (Table 1 ).

\subsection{Components of Metabolic Syndrome}

In this study, the mean systolic blood pressure (SBP) [male vs. female: $128.61 \pm 14.89$ vs. $121.97 \pm 13.13 \mathrm{mmHg}]$ and fasting blood glucose [male vs. female: $8.37 \pm 3.38$ vs. $7.26 \pm 2.81 \mathrm{mmol} / \mathrm{L}]$ were significantly higher in the male subjects than in the female subjects $[\mathrm{P}<0.05]$. Components of metabolic syndrome among male and female subjects are shown in Table1.

Table 1. Components of metabolic syndrome and thyroid function among male and female subjects $(n=346)$.

\begin{tabular}{|c|c|c|c|c|}
\hline Parameters & Male $(\mathrm{N}=79)$ & Female $(N=267)$ & Total $(\mathrm{N}=346)$ & p value \\
\hline Systolic Blood Pressure (SBP) $[\mathrm{mmHg}]$ & $128.61 \pm 14.89$ & $121.97 \pm 13.13$ & $123.48 \pm 13.81$ & $<0.001$ \\
\hline Diastolic Blood Pressure (DBP) $[\mathrm{mmHg}]$ & $82.79 \pm 7.14$ & $81.02 \pm 7.56$ & $81.43 \pm 7.49$ & 0.065 \\
\hline Waist Circumference $(\mathrm{WC})[\mathrm{cm}]$ & $89.94 \pm 7.68$ & $86.79 \pm 8.27$ & $88.82 \pm 8.13$ & 0.882 \\
\hline Fasting Blood Glucose (mmol/L) & $8.37 \pm 3.38$ & $7.26 \pm 2.81$ & $7.51 \pm 2.98$ & 0.003 \\
\hline Triglyceride (TG) [mg/dl] & $187.94 \pm 72.78$ & $178.87 \pm 65.25$ & $180.94 \pm 67.40$ & 0.292 \\
\hline High Density lipoprotein (HDL) [mg/dl] & $33.36 \pm 7.77$ & $32.98 \pm 8.09$ & $33.07 \pm 8.01$ & 0.710 \\
\hline Free Thyroxine $\left(\mathrm{FT}_{4}\right)[\mathrm{ng} / \mathrm{dL}]$ & $1.09 \pm 0.30$ & $1.05 \pm 0.19$ & $1.06 \pm 0.22$ & 0.121 \\
\hline
\end{tabular}

ANOVA analyses was done; $\mathrm{p}<0.05$ is considered as significant.

\subsection{Pattern of Thyroid Function}

Of the 346 metabolic subjects, 119 (34.4\%) had SCH, 44 (12.7\%) had clinical hypothyroidism, and 183 (52.9\%) were euthyroid. Hyperthyroidism was not detected in any of the study subject. Therefore, the overall prevalence of the thyroid dysfunctions was $47.1 \%$ in study group. Thyroid dysfunction was more common among female subjects than male subjects [female vs. male: $37.3 \%$ vs. $8.8 \%$ ] but the finding was not statistically significant; $[\mathrm{p}=0.19]$. The pattern of thyroid dysfunctions in metabolic syndrome patients is shown in Figure 1.

The mean $( \pm \mathrm{SD})$ TSH $(\mu \mathrm{IU} / \mathrm{mL})$ was $3.29 \pm 1.25$, $11.20 \pm 3.95$ and $7.18 \pm 1.40$ in euthyroid, hypothyroid and subclinical hypothyroid group respectively; [ $<<0.001]$. When the components of metabolic syndrome were compared between the thyroid dysfunction patients groups (overt hypothyroidism vs. subclinical hypothyroidism), then mean systolic blood pressure (SBP) and diastolic blood pressure (DBP) were $122.61 \pm 16.58$ vs. $122.82 \pm 14.40 \mathrm{mmHg}$; $[p=0.656]$ and $82.47 \pm 6.47$ vs. $81.25 \pm 7.00 \mathrm{mmHg}$; $[\mathrm{p}=0.612]$ respectively. The mean waist circumference (overt hypothyroidism vs. subclinical hypothyroidism) was $87.09 \pm 7.61$ vs. $87.89 \pm 7.13 \mathrm{~cm} ;[\mathrm{p}=0.102]$, and fasting blood glucose was $7.37 \pm 2.63$ vs. $7.43 \pm 3.03 \mathrm{mmol} / \mathrm{L} ;[\mathrm{p}=0.828]$. And the mean triglyceride and HDL cholesterol were $202.86 \pm 89.79$ vs. $192.98 \pm 68.46 \mathrm{mg} / \mathrm{dL} ; \quad[\mathrm{p}<0.001]$ and $34.81 \pm 7.04$ vs. $29.83 \pm 6.84 \mathrm{mg} / \mathrm{dL}$; $[\mathrm{p}<0.001]$ respectively. Among all the metabolic components, triglyceride and HDL cholesterol were significantly different across the different thyroid status groups $[\mathrm{p}<0.001]$; (Table 2). 


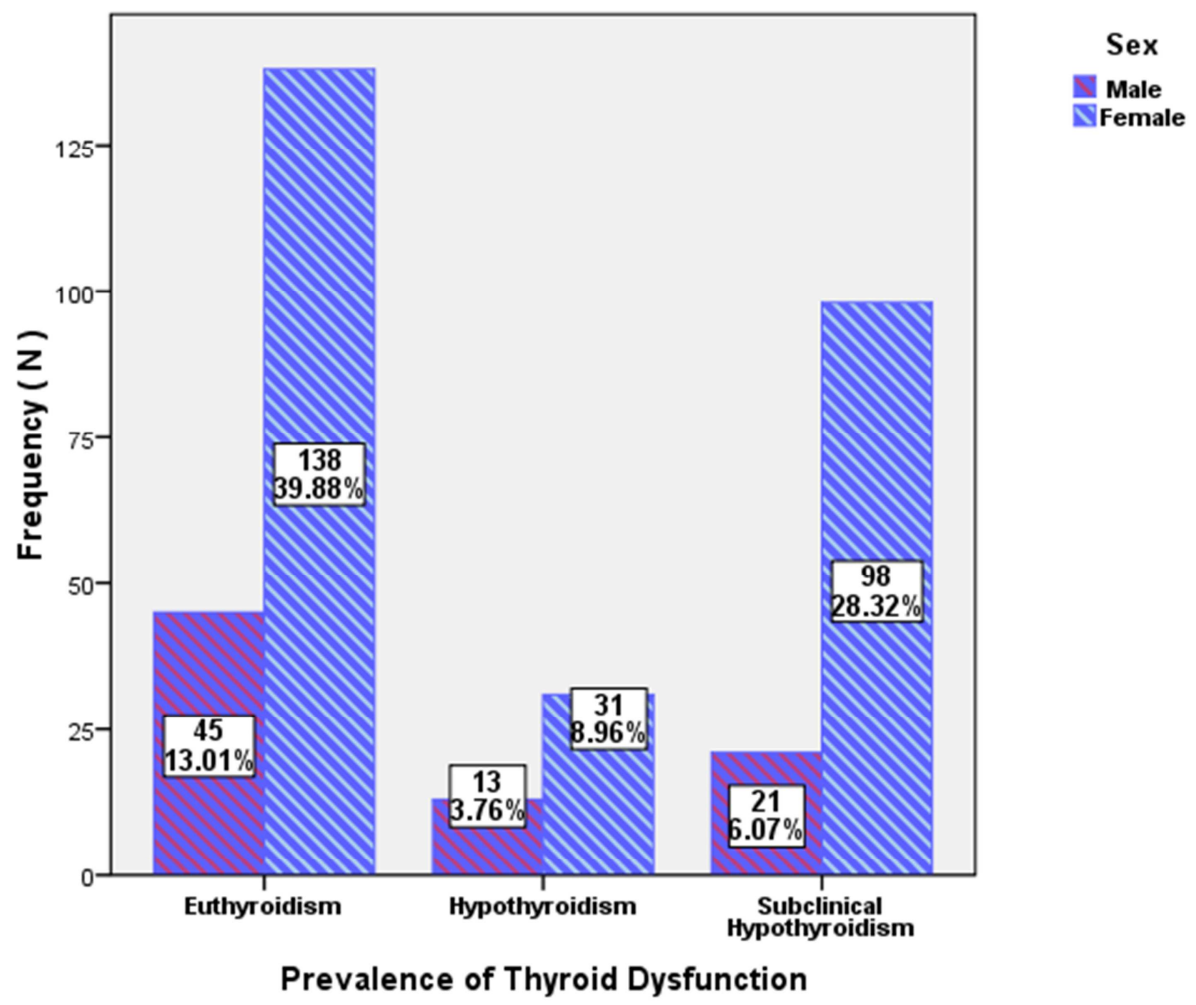

Chi-square analyses were done.

Figure 1. Prevalence of thyroid dysfunction in metabolic syndrome subjects ( $n=346)$.

Table 2. Components of metabolic syndrome and thyroid function among different thyroid status group.

\begin{tabular}{lllll}
\hline Components of metabolic syndrome & Euthyroid $(\mathbf{N}=\mathbf{1 8 3})$ & Hypothyroid $(\mathbf{N}=\mathbf{4 4})$ & Subclinical Hypothyroid $(\mathbf{N}=\mathbf{1 1 9})$ & p value \\
\hline Systolic Blood Pressure (SBP) $[\mathrm{mmHg}]$ & $124.13 \pm 12.71$ & $122.61 \pm 16.58$ & $122.82 \pm 14.40$ & 0.656 \\
Diastolic Blood Pressure (DBP) [mmHg] & $81.29 \pm 8.02$ & $82.47 \pm 6.47$ & $81.25 \pm 7.00$ & 0.612 \\
Waist Circumference (WC) [cm] & $86.07 \pm 8.80$ & $87.09 \pm 7.61$ & $87.89 \pm 7.13$ & 0.102 \\
Fasting Blood Glucose (mmol/L) & $7.60 \pm 3.03$ & $7.37 \pm 2.63$ & $7.43 \pm 3.03$ & 0.828 \\
Triglyceride (TG) [mg/dl] & $167.84 \pm 56.50$ & $202.86 \pm 89.79$ & $192.98 \pm 68.46$ & $<0.001$ \\
High Density lipoprotein (HDL) [mg/dl] & $34.75 \pm 8.31$ & $34.81 \pm 7.04$ & $29.83 \pm 6.84$ & $<0.001$ \\
TSH [ $\mu \mathrm{IU} / \mathrm{mL}]$ & $3.29 \pm 1.25$ & $11.20 \pm 3.95$ & $7.18 \pm 1.40$ & $<0.001$ \\
Free Thyroxine $\left(\mathrm{FT}_{4}\right)[\mathrm{ng} / \mathrm{dL}]$ & $1.19 \pm 0.19$ & $0.70 \pm 0.10$ & $0.98 \pm 0.68$ & $<0.001$ \\
\hline
\end{tabular}

TSH: Thyroid stimulating hormone; ANOVA analysis was done; $\mathrm{p}<0.05$ is considered as significant.

\subsection{Relation Between the Components of Metabolic Syndrome and Thyroid Function}

The current study also correlates thyroid function with some components of metabolic syndrome. The correlation between the components of metabolic syndrome and TSH and freeT4 is shown in Table 3. It showed that triglycerides were positively correlated with TSH but negatively correlated with $\mathrm{FT}_{4}[\mathrm{r}=0.168, \mathrm{P}<0.05 ; \mathrm{r}=-0.20, \mathrm{P}<0.001$ respectively]. However, HDL cholesterol negatively correlated with TSH $[\mathrm{r}=-0.150, \mathrm{P}=<0.05]$ in patients with metabolic syndrome (Figures 2-4).

Table 3. Correlation of components of metabolic syndrome with TSH and freeT4 $(n=346)$.

\begin{tabular}{|c|c|c|c|c|}
\hline \multirow{2}{*}{ Components of metabolic syndrome } & \multicolumn{2}{|l|}{ TSH } & \multicolumn{2}{|l|}{ Free $T_{4}$} \\
\hline & Pearson's Correlation & p value & Pearson's Correlation & p value \\
\hline Systolic Blood Pressure (SBP) [mmHg] & -0.062 & 0.249 & 0.053 & 0.330 \\
\hline Diastolic Blood Pressure (DBP) [mmHg] & -0.016 & 0.762 & -0.040 & 0.458 \\
\hline Waist Circumference $(\mathrm{WC})[\mathrm{cm}]$ & 0.047 & 0.385 & -0.080 & 0.140 \\
\hline Fasting Blood Glucose (mmol/L) & -0.009 & 0.867 & 0.085 & 0.114 \\
\hline Triglyceride $(\mathrm{TG})[\mathrm{mg} / \mathrm{dl}]$ & 0.168 & 0.002 & -0.20 & $<0.001$ \\
\hline
\end{tabular}

Significant using the Pearson's correlation test at $<0.05$. 


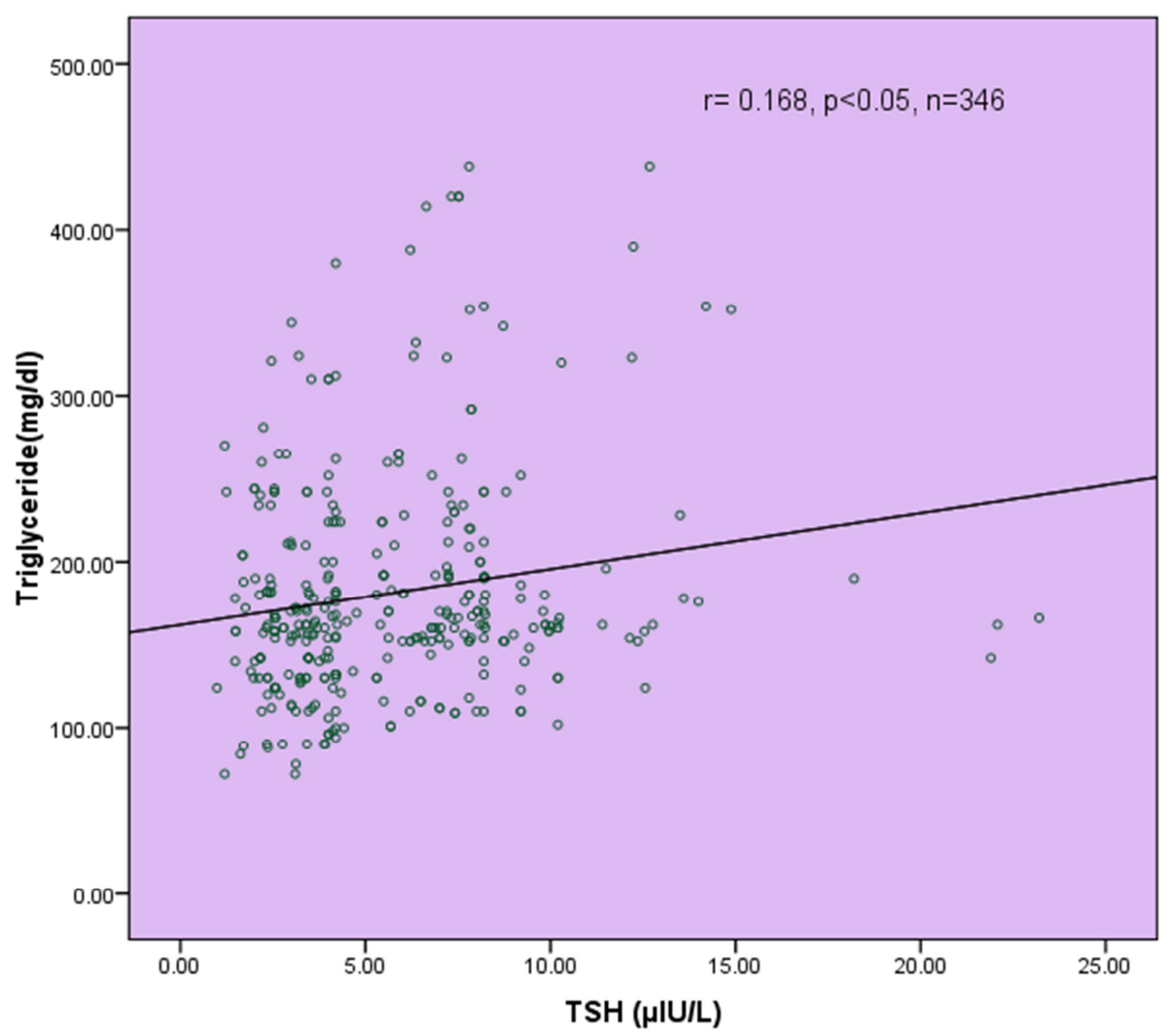

TSH: Thyroid Stimulating Hormone; r=correlation co-efficient; Significant using the Pearson's correlation test at $<0.05$.

Figure 2. Correlation between triglyceride and TSH.

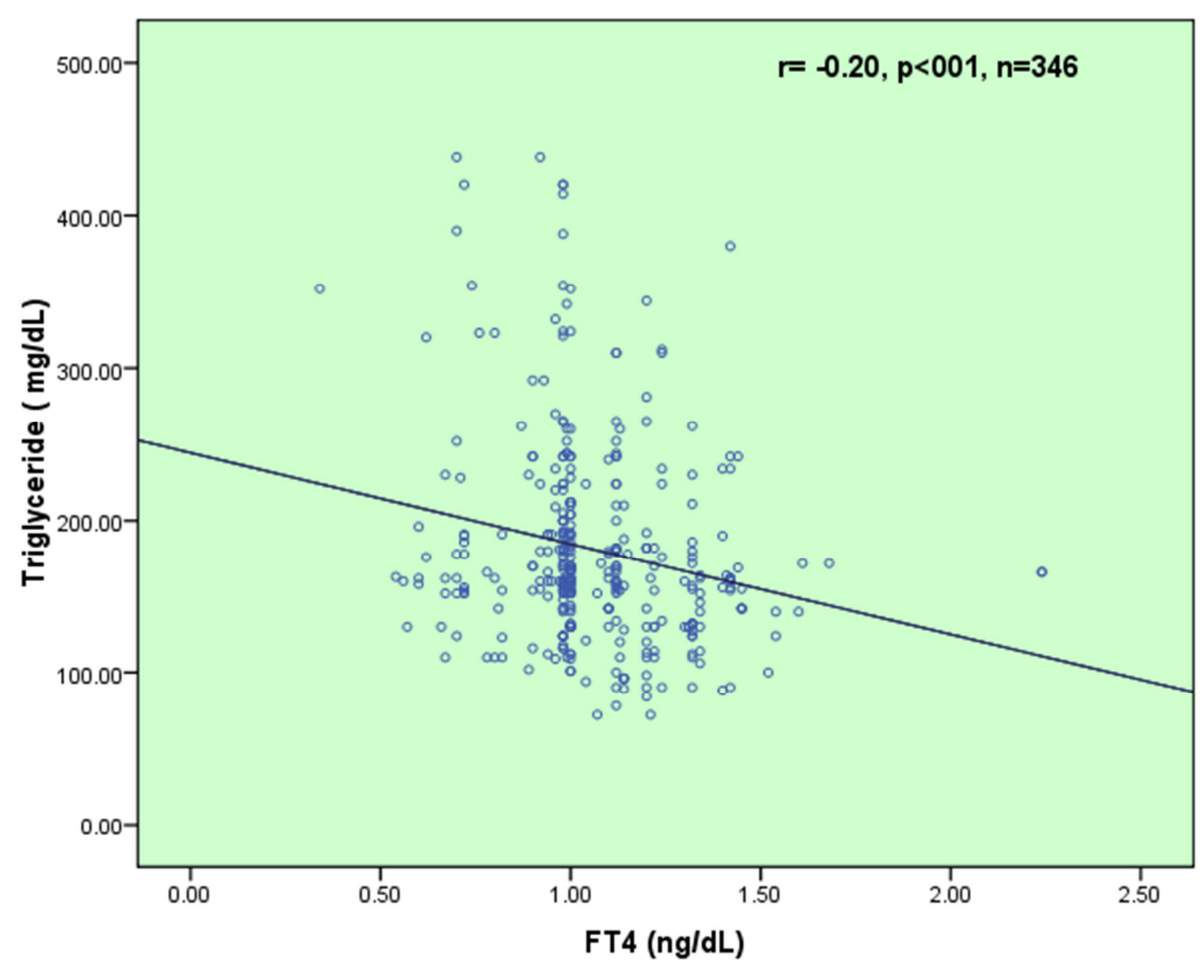

$\mathrm{FT}_{4}$ : Free Thyroxine; r=correlation co-efficient; Significant using the Pearson's correlation test at $<0.05$.

Figure 3. Correlation between triglyceride and $F T_{4}$. 


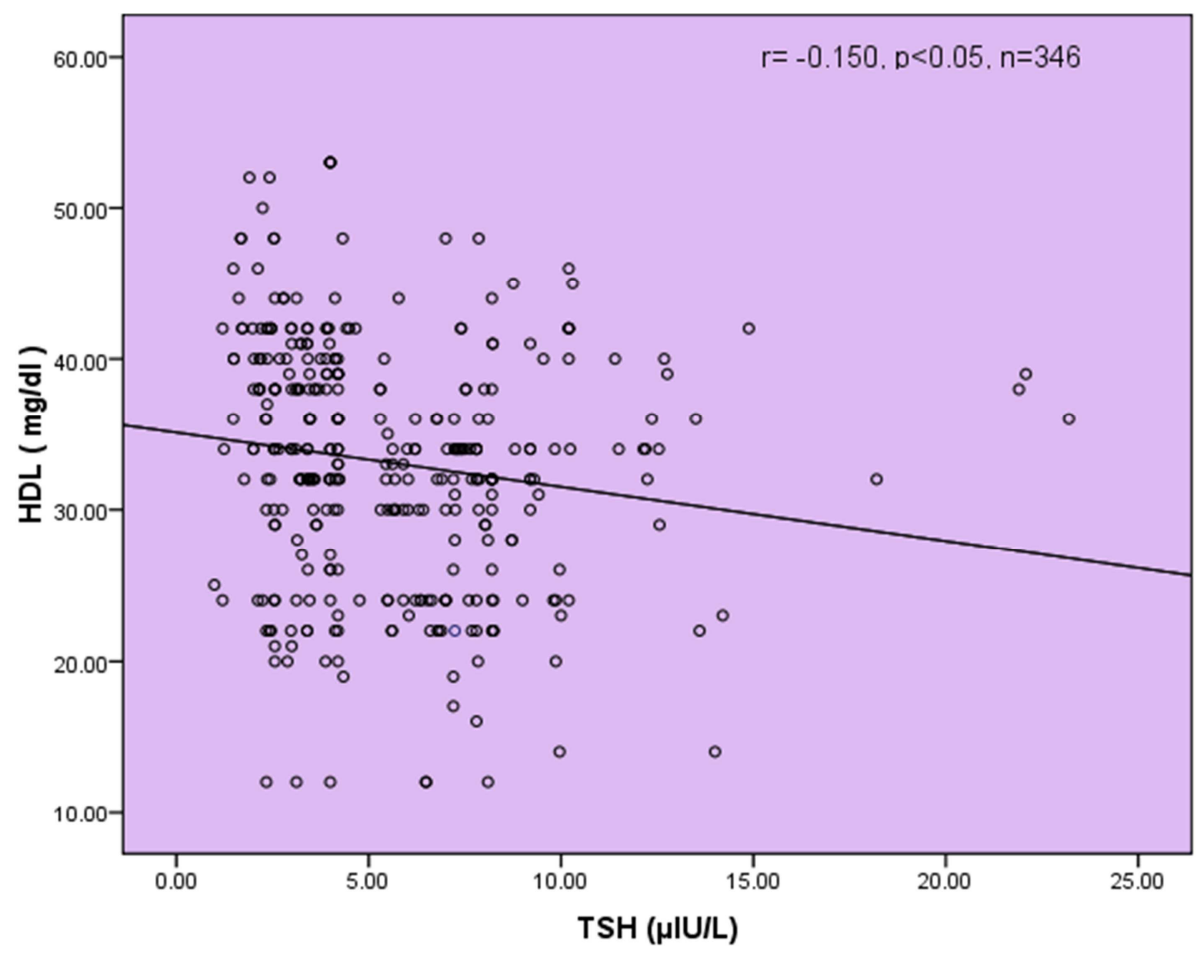

TSH: Thyroid Stimulating Hormone; HDL: High Density Lipoprotein; r=correlation co-efficient; Significant using the Pearson’s correlation test at $<0.05$.

Figure 4. Correlation between HDL cholesterol and TSH.

\section{Discussion}

Metabolic syndrome can be associated with endocrine disorders and has extensive consequences [7]. Almost all studies [7] reported a higher prevalence of metabolic syndrome in females than males. Report from a systematic review and meta-analysis of the studies in Bangladesh showed weighted pooled higher prevalence of metabolic syndrome in females (32\%) compared to males $(25 \%)$ though it was not statistically significant [7]. Though alterations of thyroid functions are well known, but still are not well approved clinically and there is discrepancy in thyroid functions in metabolic syndrome [13].

In this cross-sectional study, we observed that the prevalence of thyroid dysfunctions in MetS subjects was $47.1 \%$ and its pattern showed high prevalence of $\mathrm{SCH}$ (34.4\%) followed by hypothyroidism (12.7\%). These findings are in concurrence with previous studies revealing an association between metabolic syndrome and thyroid dysfunctions [14-16]. A previous study [14] also revealed a high prevalence of both $\mathrm{SCH}(22 \%)$ and overt hypothyroidism (4\%) in subjects with MetS. In addition, similar study from India also has shown a high prevalence of $\mathrm{SCH}(21.90 \%)$ and overt hypothyroidism $(7.40 \%)$ in patients with MetS [15]. We found thyroid dysfunction was more common in females $(37.3 \%)$ than males $(9.9 \%)$ patients, and this observation has been appeared in a number of studies including the general population [15].

Other studies have reported that the presence of Mets components in euthyroid subjects which can vary between lowest and highest serum concentrations of TSH or T4 and the prevalence of Mets increases as the normal-TSH quartile $[4,17]$. A positive association between a higher TSH level within the euthyroid reference range and the prevalence of the metabolic syndrome are also reported in many studies [6]. A study carried out in Korea [18], indicates the influence of thyroid function on metabolic abnormality and also suggested that higher levels of TSH may predict the metabolic syndrome in the study subjects. In our study, the TSH level of metabolic syndrome patients was in upper normal range, which indicates some degree of thyroid dysfunction in such patients. The upper normal reference range of TSH level was also observed in the study of Khatiwada et al. [7]. In another case control study in Nepal assessing CVD risk factors [19], the mean TSH level of healthy control population was $2.35 \pm 1.07 \mathrm{mIU} / \mathrm{L}$, which is lower than the mean TSH $(3.29 \pm 1.25 \mu \mathrm{IU} / \mathrm{mL})$ in euthyroid group of this present study.

It has been reported in a study that newly diagnosed hypothyroid patients have increased levels of cholesterol and triglyceride [20]. It was also noticed that hypothyroidism also leads to increased level of LDL cholesterol and all these factors directly contribute to accelerated atherosclerosis [20]. In a study in Nepal, it has been detected that subclinical hypothyroid patients have higher systolic blood pressure, fasting blood glucose, triglycerides and lowest HDLcholesterol compared to euthyroid subjects [7]. In the current study, subclinical hypothyroid patients had highest waist circumference and overt hypothyroid patients had highest diastolic blood pressure but euthyroid patients had highest systolic blood pressure. Highest triglyceride and lowest HDL cholesterol were seen in patients with overt hypothyroidism 
and subclinical hypothyroidism respectively. Highest fasting blood sugar was seen in euthyroid patients.

Thyroid hormones affect lipid metabolism and thus the components of metabolic syndrome, and there is positive relation between TSH and LDL cholesterol, whereas negative relation between TSH and HDL cholesterol [19]. However, there are diverging reports about the association between different parameters of metabolic syndrome and thyroid function [19]. In a study in Nigeria [21], metabolic syndrome was significantly associated with higher free T4 levels. In another study in India [14], significant association was found in between $\mathrm{SCH}$ and metabolic syndrome and a linear association was noted between TSH levels and total cholesterol, triglycerides, LDL, and HDL cholesterol levels across the metabolic syndrome subjects. However, in a study in Turkey, no relation was observed in between TSH and any metabolic syndrome parameters [22]. In our study, TSH was found to bear a significant positive correlation with triglyceride; but TSH was negatively correlated to HDL-C. Negative correlation was also seen between FT4 and triglyceride. Similar observations were also detected in a study by Roos et al. [4].

\section{Limitation}

The present study has however few limitations. First, a cause and effect of relationship could not be determined from this cross-sectional study. Second, the small sample size of our study could have led to false negative results as far as some of the correlations are concerned. Third, it has been found that both iodine deficiency and excess can lead to thyroid disorder particularly subclinical hypothyroidism. But the iodine nutrition status in the patients of our study was not assessed. Further cohort study of large sample is needed to evaluate the deleterious effect of thyroid dysfunctions on cardiovascular disease and metabolic functions.

\section{Conclusion}

Our study finds high prevalence of thyroid dysfunction specifically subclinical hypothyroidism in the patients with metabolic syndrome. We also observe thyroid hormone significantly affects and associated with components of metabolic syndrome (triglyceride and HDL cholesterol). Present study findings suggest that subclinical hypothyroidism is known to be associated with metabolic syndrome and increased compound risk for cardiovascular diseases. Therefore it should be considered as one of the new component in newly diagnosed metabolic syndrome patients in future. Further studies are needed to detect the mechanism of this correlation and to clear the debate whether patients with subclinical hypothyroidism should be treated routinely for cardiovascular benefits or not.

\section{Ethical Approval}

The ethical approval was obtained from the ethics review board of the hospital.

\section{Declaration of Conflicting Interests}

Nothing to declare.

\section{References}

[1] Gyawali P, Takanche JS, Shrestha RK, Bhattarai P, Khanal K, Risal P, et al. Pattern of thyroid dysfunction in patients with metabolic syndrome and its relationship with components of metabolic syndrome. Diabetes Metab J. 2015; 39 (1): 66-73.

[2] Grundy SM. Obesity, metabolic syndrome, and cardiovascular disease. J Clin Endocrinol Metab. 2004; 89 (6): 2595-600.

[3] Michalaki MA, Vagenakis AG, Londu AS, Marianna NA, Ioannis GH, Makri MG, et al. Thyroid function in humans with morbid obesity. Thyroid. 2006; 16 (1): 73-78.

[4] Roos A, Bakker SJL, Links TP, Gans ROB, Wolffenbutte 1BHR. Thyroid Function Is Associated with Components of the Metabolic Syndrome in Euthyroid Subjects. J Clin Endocrinol Metab. 2007; 92 (2): 491-6.

[5] Ghanshyam P, Subash S, Anita A, Kumar V. Association between primary hypothyroidism and metabolic syndrome and the role of $\mathrm{C}$ reactive protein: a cross-sectional study from South India. Thyroid Research. 2009; 2 (2): 1-7.

[6] Waring AC, Rodondi N, Harrison S, Kanaya AM, Simonsick EM, Miljkovic I, et al. Thyroid Function and Prevalent and Incident Metabolic Syndrome in Older Adults: The Health, Aging, and Body Composition Study. Clin Endocrinol (Oxf). 2012; 76 (6): 911-8.

[7] Khatiwada1 S, Sah SK, Rajendra KC, Baral N, Lamsal M. Thyroid dysfunction in metabolic syndrome patients and its relationship with components of metabolic syndrome. Clinical Diabetes and Endocrinology. 2016; 2: 3 . DOI: 10.1186/s40842-016-0021-0.

[8] Chowdhury MZI, Anik AM, Farhana Z, Bristi PD, Mamun BMA, Uddin MJ, et al. Prevalence of metabolic syndrome in Bangladesh: a systematic review and meta-analysis of the studies. BMC Public Health. 2018; 18: 308. https://doi.org /10. 1186/s12889-018-5209-z.

[9] International diabetes federation, the IDF consensus worldwide definition of the metabolic syndrome. https:// www. idf.org/e-library/consensus-statements/60-idfconsensusworldwide-definition-of-the-metabolic-syndrome. Accessed 10 Aug 2017.

[10] Karar ZA, Alam N, Streatfield PK. Epidemiological transition in rural Bangladesh, 1986-2006. Glob Health Action. 2009; 2: 1904.

[11] Executive summary of the third report of the national cholesterol education program (NCEP) expert panel on detection, evaluation, and treatment of high blood cholesterol in adults (Adult Treatment Panel III). JAMA. 2001; 285: 2486

[12] Smith Liz. New AHA recommendations for blood pressure measurement: American Heart Association Practice Guidelines. Am Fam Physician. 2005; 72 (7): 1391-98. 
[13] Chugh K, Goyal S, Shankar V, Chugh SN. Thyroid function tests in metabolic syndrome. Indian J Endocrinol Metab. 2012; 16 (6): 958-61.

[14] Meher LK, Raveendranathan SK, Kota SK, Sarangi J, Jali SN. Prevalence of hypothyroidism in patients of metabolic syndrome. Thyroid Res Pract. 2013; 10: 60-4.

[15] Shantha GP, Kumar A A, Jeyachandran V, Rajamanickam D, Rajkumar K, Salim S, et al. Association between primary hypothyroidism and metabolic syndrome and the role of $\mathrm{C}$ reactive protein: a cross-sectional study from South India. Thyroid Res. 2009; 2: 2.

[16] Wang JY, Wang CY, Pei D, Lai CC, Chen YL, Wu CZ, et al. Association between thyroid function and metabolic syndrome in elderly subjects. J Am Geriatr Soc. 2010; 58: 1613-4.

[17] Park HT, Cho GJ, Ahn KH, Shin JH, Hong SC, Kim T, et al. Thyroid stimulating hormone is associated with metabolic syndrome in euthyroid postmenopausal women. Maturitas. 2009; 62 (3): 301-5.

[18] Park SB, Choi HC, Joo NS. The Relation of Thyroid Function to Components of the Metabolic Syndrome in Korean Men and Women. J Korean Med Sci. 2011; 26 (4): 540-5.

[19] Kc R, Khatiwada S, Deo Mehta K, Pandey P, Lamsa 1M, Majhi S. Cardiovascular Risk Factors in Subclinical Hypothyroidism: A Case Control Study in Nepalese Population. J Thyroid Res. 2015; 2015: 305241. doi: $10.1155 / 2015 / 305241$.

[20] Gluvic Z, Sudar E, Tica J, Jovanovic A, Zafirovic S, Tomasevic R, et al. Effects of levothyroxine replacement therapy on parameters of metabolic syndrome and atherosclerosis in hypothyroid patients: a prospective pilot study. Int J Endocrinol. 2015; 2015: 147070.

[21] Udenze I, Nnaji I, Oshodi T. Thyroid function in adult Nigerians with metabolic syndrome. Pan Afr Med J. 2014; 18: 352. doi: 10.11604/pamj.2014.18.352.4551.

[22] Tarcin O, Abanonu GB, Yazici D, Tarcin O. Association of metabolic syndrome parameters with TT3 and FT3/FT4 ratio in obese Turkish population. Metab Syndr Relat Disord. 2012; 10 (2): $137-42$. 